\title{
Comparison of leukocyte excretion and blood loss in inflammatory disease of the bowel
}

\author{
K Teahon, I Bjarnason
}

\begin{abstract}
Clinical relapse of inflammatory bowel disease is characterised by increased neutrophil migration into the intestine. The site of the neutrophil chemoattractant(s), whether luminal or mucosal, may be important since, on contact with a chemoattractant, neutrophils cause indiscriminate damage to their immediate surroundings by generating reactive oxygen species and by lysosomal enzyme release. If this happens within the mucosa, inflammation should correlate significantly with tissue damage as assessed by bleeding, but if it occurs within the intestinal lumen, the inflammation would be disproportionately greater than the bleeding such as is seen in classical exudation. Intestinal inflammation and bleeding were quantitated with the simultaneous use of indium-111 labelled neutrophils (four day faecal excretion of indium-111) and chromium-51 labelled red cells in patients with ulcerative colitis $(n=12)$, Crohn's disease $(n=15)$, and NSAID induced enteropathy $(n=34)$. Intestinal inflammation and blood loss correlated significantly (Spearman) in patients with ulcerative colitis $(20.3 \% \quad v \quad 6.5 \mathrm{ml} / \mathrm{d}$ (median) r: 0.85, p<0.001) and NSAD enteropathy $(1.6 \%$ v $1.9 \mathrm{ml} / \mathrm{d}, \mathrm{r}: 0.60, \mathrm{p}<0.01)$ but not in Crohn's disease $(17.0 \% v 2.1 \mathrm{ml} / \mathrm{d}, \mathrm{r}: 0.38$, $p>0 \cdot 1)$. For a given indium-111 excretion, patients with ulcerative colitis had significantly greater $(p<0.01)$ blood loss than patients with Crohn's disease. These results suggest that the predominant site of neutrophil chemoattractants may be within the mucosa in ulcerative colitis and NSAID enteropathy and within the lumen in Crohn's disease.

(Gut 1993; 34: 1535-1538)
\end{abstract}

The study of humoral and cellular immunopathogenesis of inflammatory bowel disease has received much interest. ${ }^{1-3}$ The most characteristic feature of clinical relapse is the increased flux of neutrophils into the intestine. ${ }^{46}$ Understanding the movement of neutrophils and the mechanisms through which they mediate tissue injury is fundamental to elucidating the pathogenesis of relapse.

Although controversial, ${ }^{78}$ it now seems likely that the striking 'in vitro' findings ${ }^{9}{ }^{10}$ of reduced neutrophil mobilisation and altered function in patients with inflammatory bowel disease are not intrinsic to the cell but reflect neutrophil conditioning by different inflammatory milieu. Study of indium-111 labelled neutrophils shows close similarities between ulcerative colitis and Crohn's disease in respect of the quantity and kinetics of neutrophil migration from blood to lumen across the intestinal mucosa. ${ }^{+}$The question then arises as to the site and nature of the neutrophil chemoattractant. The latter has been extensively studied by Stenson, "who suggested a two stage pathogenic framework for inflammatory bowel disease. He proposes that there is an as yet unknown triggering event which initiates an early neutrophil influx. Subsequent to this there is an amplified second phase of neutrophil chemotaxis which is much greater than the original. There is compelling evidence to suggest that the second amplification stage is mediated by leukotriene $\mathrm{B}_{4}$, a lipo-oxygenase product released by the neutrophils themselves. ${ }^{12} 13$

It is clear that whatever the primary or secondary chemoattractant is the neutrophils destined for it will respond in a predictable fashion. ${ }^{14}$ is $\mathrm{On}$ contact with the chemoattractant they form oxygen reactive species and there is release of lysosomal enzymes after phagocytosis. Both of these mechanisms may destroy the chemoattractant but will also cause unavoidable nonspecific damage in the immediate vicinity of the neutrophil. ${ }^{14}$ is

The site of neutrophil chemoattractants may therefore be an important determinator of the secondary damage (as assessed by blood or protein loss) caused by neutrophils. This is particularly well demonstrated in the experimental animal where the emigration of neutrophils through the intestinal mucosa in response to a luminal chemoattractant does not cause tissue damage while intracutaneous inoculation of the same substance does. ${ }^{16}$

In an attempt to localise, in vivo, the site of neutrophil chemoattractants in patients with ulcerative colitis and Crohn's disease, we used a dual isotope method to quantitate simultaneously intestinal inflammation and blood loss. We argued from the above that the two should correlate closely if the neutrophils are seeking a mucosal chemoattractant, less so if the chemoattractant is in the lumen, in which case the inflammation should be disproportionally greater than the blood loss. Patients on nonsteroidal anti-inflammatory drugs (NSAID) acted as a control group. ${ }^{1718}$ There is some evidence to suggest that the neutrophil chemoattractant in NSAID enteropathy may be a metronidazole sensitive microbe. ${ }^{19}$

Subjects and methods

Patients were recruited from gastroenterology and rheumatology outpatient clinics at Northwick Park Hospital. All patients gave fully informed consent to the studies which were approved by the Harrow Health Authority Ethical Committee. 
INFLAMMATORY BOWEL DISEASE

Twelve patients with ulcerative colitis (eight pancolitis and four left sided colitis; age 22-70 years; five were on sulphasalazine and two on prednisolone 10 and $30 \mathrm{mg}$ ) and 15 patients with Crohn's disease (one of whom had undergone ileal resection) (six ileal and pancolitis, one left sided colitis, six ileal and two small intestinal; age 18-70 years; 13 were on no treatment, one on $10 \mathrm{mg}$ prednisolone and one on sulphasalazine) were studied. There were no significant differences in haemoglobin; white cell and platelet counts; erythrocyte sedimentation rate; or clinical disease activity ${ }^{20}$ between patients with ulcerative colitis and those with Crohn's disease. After the indium-111 and 51-chromium excretion studies all patients had a full colonoscopy or double contrast barium enema to confirm the diagnosis and to evaluate the extent of disease.

\section{PATIENTS WITH RHEUMATOID ARTHRITIS}

Thirty four patients with rheumatoid arthritis were studied. The patients had been on treatment for more than six months and although the type of NSAID varied, all had been established on one drug continuously for over six weeks. Twenty patients were on concomitant, second line agents (nine colchinine, six gold im, five penicillamine); but we have previously shown that these drugs do not affect the frequency or severity of the small intestinal inflammation caused by NSAIDs. ${ }^{1718}$

\section{INDIUM LABELLING STUDIES}

An indwelling catheter was placed in an anticubital vein. Six millilitres of blood were drawn into a syringe containing $11 \mathrm{ml}$ of acid citrate dextrose (National Institutes of Health formula A), dispensed into two sterile polythene tubes, and allowed to sediment for one hour at room temperature. The supernatant was removed and centrifuged at $100 \mathrm{~g}$ for five minutes. The resultant supernatant was removed immediately and respun at $300 \mathrm{~g}$ to yield a cell free plasma. The pellet from the $100 \mathrm{~g}$ centrifugation was resuspended and incubated for 10 minutes at room temperature in 0.1 HEPES saline buffer (pH 7.4) containing $20 \mathrm{mM}$ HEPES in $0.8 \%$ sodium chloride, $4.4 \mathrm{mM}$ tropolone and $300 \mu \mathrm{Ci}$ (11 $\mathrm{MBq}$ ) indium-111 chloride (Amersham International). Five millilitres of cell free plasma were added to the cell suspension and centrifuged at $100 \mathrm{~g}$ for five minutes. The suspension containing the unlabelled indium-111 was poured off and the labelled cells were resuspended in $6 \mathrm{ml}$ of cell-free plasma. Five millilitres (7-9 MBq) were injected and the rest used for standards. The labelling efficiency by this technique averages $84 \%$ (range $74-93 \%$ ). ${ }^{56}$ The leukocytes maintain their integrity and function during this procedure.

Abdominal scintigrams were obtained at one to four hours and 20 hours after injection of the labelled cells, to localise the site and extent of disease using an IGE 400 AT gamma camera with a STAR computer at the appropriate channel settings.

Individual faecal excretions were collected over a four day period in $500 \mathrm{ml}$ polythene clip top containers. Standards $(0 \cdot 1 \mathrm{ml}$ aliquots of the labelled cells) were made up to $50 \mathrm{ml}$ with water and distributed over a fixed amount of filter paper in an identical container. Both samples and standard were individually counted in a high resolution bulk sample counter as previously described. ${ }^{21}$ Counts were made for 20 seconds, which allows the measurement of $0.01 \%$ of the injected dose with a counting accuracy of $\pm 4 \%$. Each count was then corrected for any chromium-51 crossover into the indium-111 channel which is negitable if performed on completion of the study. Normal excretion values had been obtained in patients with the irritable bowel syndrome $(n=14)$ who excreted $0.5 \%$ (mean) with an upper limit of normal at $1 \%$.

\section{BLOOD LOSS STUDIES}

At the same time as blood was obtained for leukocyte labelling, $10 \mathrm{ml}$ were dispensed into 40 $\mathrm{ml}$ of citrate-phosphate-dextrose solution containing trisodium citrate dihydrate $3(\mathrm{w} / \mathrm{v})$; sodium dihydrogen phosphate $0.015(\mathrm{w} / \mathrm{v})$; dextrose $0.2(\mathrm{w} / \mathrm{v})$ at $\mathrm{pH}$ of 6.9 . The solution was centrifuged at $1000 \mathrm{~g}$ for 10 minutes, the supernatant was discarded and $1.5 \mu \mathrm{Ci} / \mathrm{kg}$ body weight of disodium (51) chromate was added dropwise to the pellet of red cells while mixing gently. The pellet was allowed to stand at room temperature for 15 minutes to allow binding to occur and unbound 51-chromium was then removed by washing with $0.9 \%$ saline. The final pellet was made up to $10 \mathrm{ml}$ with saline before injection into the patient.

Individual faecal excretions were made for five days in conjunction with the indium-111 neutrophil studies. Standards were made up by drawing $5 \mathrm{ml}$ of venous blood daily for four days after injection of the labelled red cells. Four ml were distributed over a fixed amount of filter paper in a faecal collection container. Once the indium- 111 counting was completed the samples were stored for four to six weeks to allow decay of the indium-111. Each count was corrected for any possible spillover of residual indium-111. The chromium-51 activity in the stools was correlated with the chromium-51 activity in blood from the previous day which allows quantitation of intestinal blood loss. The upper normal limit of intestinal blood loss is $1.0 \mathrm{ml} /$ day. Using a $300 \mu \mathrm{Ci}(11 \mathrm{MBq})$ injection of indium-111 and a $100 \mu \mathrm{Ci}(4 \mathrm{MBq})$ injection of chromium-51 the estimated radiation dose received by the patient during these studies is $7 \cdot 2$ milli Sieverts (effective dose equivalent).

\section{STATISTICAL ANALYSIS}

Wilcoxon's rank sum test was used for nonparametric data to analyse the mean values, which are given as median and interquartile range. Spearman's rank correlation coefficient was used to correlate between inflammation and bleeding. The sign test was used to assess the differences in red cell loss (using the square root data) between patients with ulcerative colitis and those with Crohn's disease for a given level of inflammation. 
Inflammation and blood loss in inflammatory bowel disease and NSAID induced enteropathy

\begin{tabular}{lcl}
\hline & 111 -In leukocytes $(n<1 \%)$ & ${ }^{51}$ Cr red blood cells $(n<1 \mathrm{ml} / \mathrm{d})$ \\
\hline Ulcerative colitis & $20 \cdot 3 \%(8 \cdot 3-53 \cdot 1 \%)$ & $6 \cdot 5 \mathrm{ml} / \mathrm{d}(1 \cdot 8-29 \cdot 2 \mathrm{ml} / \mathrm{d})$ \\
Crohn's disease & $17 \cdot 0 \%(12 \cdot 1-22 \cdot 0 \%)$ & $2 \cdot 1 \mathrm{ml} / \mathrm{d}(0 \cdot 7-5 \cdot 3 \mathrm{ml} / \mathrm{d})^{\star}$ \\
Patients on NSAIDs & $1 \cdot 6 \%(0 \cdot 7-3 \cdot 0 \%)^{\star \star}$ & $1 \cdot 9 \mathrm{ml} / \mathrm{d}(0.5-3.8 \mathrm{ml} / \mathrm{d})^{\star \star \star}$ \\
\hline
\end{tabular}

Values represent median (interquartile range).

${ }^{\star}$ Differs significantly from ulcerative colitis $(\mathrm{p}<0.05) ;{ }^{\star \star}$ differs significantly from ulcerative colitis and Crohn's disease $(p<0 \cdot 05) ; \star \star \star$ differs significantly from ulcerative colitis but not from Crohn's disease $(p<0.05)$.

$\mathrm{n}=$ normal. correlation ( $\mathrm{r}: 0 \cdot 60, \mathrm{p}<0 \cdot 01)$ between inflammation and blood loss in patients taking NSAIDs.

\section{Discussion}

The techniques of indium-111 labelled neutrophils and chromium-51 red cells are well described $^{462223}$ and are accurate, specific, and sensitive methods for quantitating intestinal inflammation and blood loss. The indium-111 leukocyte technique is particularly suitable for the present study since it utilises the homing properties of neutrophils in response to specific chemoattractants. Its simultaneous use with labelled red cells shows the specificity of the technique and the selectivity of neutrophil migration to the intestine in these disorders. Thus, as neutrophils are normal constituents of blood it would seem possible that the faecal excretion of indium-111 simply reflected nonspecific intestinal bleeding or oozing (for example, vascular injury due to eroding ulcers). If this was indeed the case, then each $1 \%$ of injected neutrophils excreted in faeces should be associated with equivalent blood loss. However, $1 \%$ of the circulating blood volume in an average person (five litres) is $50 \mathrm{ml}$. Clearly, the excretion of the neutrophils is considerably greater than could be accounted for simply by bleeding. Of the various neutrophil functions - namely adherence, aggregation, orientation, locomotion, and chemotaxis - few are better defined and understood than the sequence of events when the neutrophil comes into contact with a chemoattractant. ${ }^{15426}$ On contact free radical species are generated via nicotinamide adenine dinucleotide phosphate linked oxidase, flavoproteins, cytochrome $b$, and myeloperoxidase. Concomitant phagocytosis internalises the chemoattractant for further degradation with subsequent lysosomal enzyme release. Both mechanisms, however, cause indiscriminate damage in the immediate vicinity fo the neutrophil. The idea that damage relates to the localisation of the chemoattractant, whether mucosal or luminal, is supported by data in the experimental animal. ${ }^{16} 27$

Although the pathogenesis of the three disorders is uncertain, that of NSAID enteropathy is probably best understood..$^{17} 1828$ NSAIDs cause direct cellular damage during drug absorption by several interacting actions on intermediary metabolism. ${ }^{29}$ The mucosa is further compromised because of the effect of NSAIDs on cyclooxygenase, effectively preventing the production of reparative prostaglandins. ${ }^{30}$ Damaged intercellular junctions allow increased permeation of luminal substances, which by itself seems to be insufficient to elicit detectable neutrophil chemoattraction. Indeed inflammation is only consistently evident after six months of NSAID ingestion and may be due to a metronidazole sensitive microbe. ${ }^{19}$ The driving force for inflammation then is a combination of drug and luminal induced mucosal damage. Although not directly comparable (because of the different range of indium-111 faecal excretion) it seems that there is similar blood loss in NSAID treated patients and patients with Crohn's disease, although the inflammatory activity was 10 fold higher in the
Figure 2: The correlation between intestinal inflammation and mean daily blood loss in patients with rheumatoid arthritis on NSAIDs.

\section{Results}

The Table shows that there was no significant
difference in the four day faecal excretion of indium-111 between patients with ulcerative
colitis or Crohn's disease. Figure 1 shows that there is a significant correlation between the inflammation and blood loss in patients with
ulcerative colitis ( $\mathrm{r}: 0.85, \mathrm{p}<0.002$ (two sided test)) but not in those with Crohn's disease $(\mathrm{r}: 0 \cdot 38, \mathrm{p}>0 \cdot 1)$. At a given faecal excretion of colitis have significantly greater blood loss p $<0.01)$ than patients with Crohn's disease. Crohn's disease were analysed separately there excretion of indium-111 leukocytes and chromium 51 red cells, and the lack of significant evident in both subgroups (small bowel Crohn's $(r=-0.08, p=0 \cdot 80)$ and large bowel Crohn's
$(r=0.39, p=0.30))$. Moreover, for a given faecal excretion of indium-111, patients with both ulcerative colitis

had significantly less inflammation than patients loss was similar to that of patients with Crohn's disease. Figure 2 shows that there is a significan

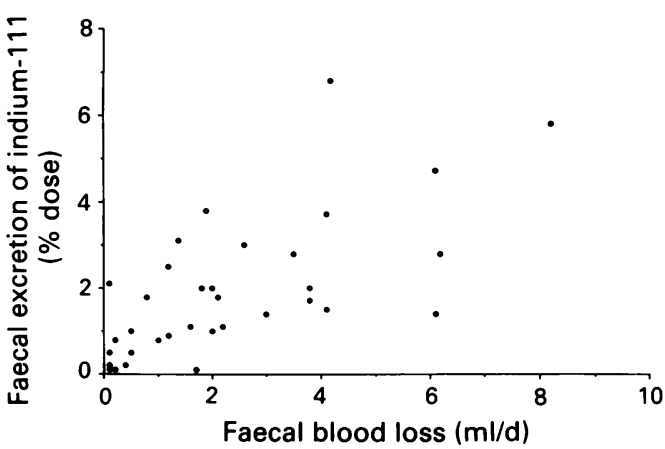


latter. Combined with the rather weak correlation between inflammation and bleeding (r: $0 \cdot 60$ ), this suggests that while most of the neutrophils are seeking a mucosal signal, some may also be destined for the lumen in NSAID induced enteropathy.

In inflammatory bowel disease the initial or predisposing event is unknown. The relapse, however, may be due to a chemoattractant with secondary amplification by local neutrophil leukotriene production and it is of note that twice as many leukotrienes are found in ulcerative colitis mucosa than in Crohn's disease. ${ }^{31}{ }^{32}$ The different results obtained in this study in patients with ulcerative colitis and Crohn's disease agrees with many clinical and experimental observations. It confirms the clinical dictum that patients with ulcerative colitis often present with a greater degree of blood loss than patients with Crohn's disease, ${ }^{33}$ and that this is not simply a matter of being concealed (or occult) in Crohn's disease. The data are consistent with detailed histopathological assessment showing that the mucosal neutrophils in ulcerative colitis are activated and show ultrastructural evidence of phagocytosis and granular extrusion. ${ }^{34}$ In Crohn's disease, however, where the mononuclear cell infiltrate is both transmural and patchy, the neutrophils are mainly centred around ulcers and show little evidence of the activation that occurs on contact with a chemoattractant. The prominence of a luminal neutrophil chemoattractant in active Crohn's disease may partly explain the observation that treatments directed towards altering the luminal milieu (elemental diets, total parentral nutrition, and diversion surgery) are consistently as effective for active Crohn's disease as they are ineffective for patients with ulcerative colitis. ${ }^{35-37}$ Luminal factors also seem to be important in the recurrence of disease after surgery. ${ }^{38} 39$ The precise nature of neutrophil chemoattractants in these disorders is unknown and they could be of a diverse nature including microbial, chemical (including prostanoids) or indeed in ulcerative colitis the damaged colonocytes themselves.

In conclusion, the acute inflammatory infiltrate and bleeding go hand in hand in active ulcerative colitis and in patients taking NSAIDs, suggesting that the main neutrophil chemoattractant(s) is within the mucosa. In Crohn's disease there is disproportionally greater inflammation than blood loss and the lack of correlation between the two suggests that the predominant site of the chemoattractants is within the gut lumen.

Thanks to Drs M J Gumpel and A J Levi for allowing us to study patients attending their outpatient clinics.

1 Strober W, James SP. The immunologic basis of inflammatory bowel disease. 7 Clin Immunol 1986; 6: 415-32.

2 James SP, Strober W, Quinn TC, Danovitch SH. Crohn's disease. New concepts of pathogenesis and curren disease. New concepts of pathogenesis and current

3 Shorter RG, Huizenga KA, Spencer RJ. A working hypothesi for the aetiology and pathogenesis of non-specific inflammafor the aetiology and pathogenesis of non-specific

4 Saverymuttu SH, Peters AM, Lavender JP, Hodgson HJ, Chadwick VS. Indium-111 autonder leucocytes in inflamChadwick VS. Indium-111 autologous leu

5 Saverymuttu SH, Peters AM, Lavender JP, Pepys MB Hodgson HSF, Chadwick VS. Quantitative faecal indium111 labelled leucocyte excretion in assessment of diseas activity in Crohn's disease. Gastroenterology 1983; 85: $1333-9$

6 Teahon K, Smethurst P, Pearson M, Levi AJ, Bjarnason I The effect of elemental diet on intestinal permeability and inflammation in Crohn's disease. Gastroenterology 1991; 101 : 84-9.

7 Curran FT, Allan RN, Keighley MRD. Superoxide production by Crohn's disease neutrophils. Gut 1991; 32: 399-402.

8 Verspaget HW, Mieremet-Coms MAC, Weterman IT, Pen AS. Partial defect of neutrophilic oxidative metabolism in Crohn's disease. Gut 1984; 25: 849-53.

9 O'Morain C, Segal AW, Walker D, Levi AJ. Abnormalities of neutrophil function do not cause the migration defect in Crohn's disease. Gut 1981; 22: 817-22.

10 Wandall JH. Neutrophilic granulocyte function. Danish Med Bull 1988; 22: 817-22.

11 Stenson WF. Arachidonic acid metabolites in inflammatory bowel disease. Advances in Inflammation Research 1988; 12 215-22.

12 Lobos EA, Sharon P, Stenson WF. Chemotactic activity in inflammatory bowel disease: role of leukotriene $\mathrm{B}_{4}$. Dig $\mathrm{Di}$ Sci 1987; 32: 1380-8.

13 Sharon P, Stenson WF. Enhanced synthesis of leucotriene B by colonic mucosa in inflammatory bowel disease. Gastroenterology 1984; 86: 453-60.

14 Malech ML, Callin JI. Neutrophils in human disease. $N E n g$ F Med 1987; 317: 687-94.

15 Weiss SJ. Tissue destruction by neutrophils. $N$ Engl f Med 1989; 320: 365-76.

16 Bellamy JEC, Nielsen NO. Immune mediated emigration of neutrophils into the lumen of the small intestine. Infect Immun 1974 $9: 615-9$.

17 Bjarnason I, Zanelli G, Smith T, Prouse P, Williams P Smethurst $\mathrm{P}$, et al. Non-steroidal anti-inflammatory drug induced intestinal inflammation in man. Gastroenterology induced intestinal

18 Bjarnason I. Non-steroidal anti-inflammatory drug-induced small intestinal inflammation in man. In: Pounder $R$, ed. Recent advances in Gastroenterology - 7. Edinburgh Churchill Livingstone, 1988: 23-46.

19 Bjarnason I, Hayllar J, Smethurst P, Price AB, Gumpel MJ. Metronidazole reduces intestinal inflammation and blood loss in non-steroidal anti-inflammatory drug induced enteropathy. Gut 1992; 33: 1204-8.

20 Harvey RF, Bradshaw JM. A simple index of Crohn's disease activity. Lancet 1980 ; i: 514 .

21 Bjarnason I, Zanelli G, Prouse P, Smethurst P, Smith T, Levi $\mathrm{S}$, et al. Blood and protein loss via small intestinal inflammation induced by non-steroidal anti-inflammatory drugs. tion induced by non-

22 Mollison PL, Veall N. The use of the isotope ${ }^{51} \mathrm{Cr}$ as a label for red cells. Brf Haematol 1955; 1: 62-74.

23 Scott JT, Porter IH, Lewis SM, Dixon AStJ Studies of gastrointestinal bleeding caused by corticosteroids, salicylates and other analgesics. Qf Med 1961; 30: 167-87.

24 Segal AW, Jones OTG. Novel cytochrome b system in phagocytic vacuoles from human granulocytes. Nature 1978 276: 515-7.

25 Bellavite $P$. The superoxide-forming enzyme system of phagocytes. Free Radic Biol Med 1988; 4: 225-61.

26 Segal AW. The electron transport chain of the mitochondrial oxidase of phagocytic cells and its involvement in the molecular pathology of chronic granulomatous disease. In Peters TJ, ed. The cell biology of inflammation in the gastrointestinal tract. Hull: Corner Publication, 1990: 51-73.

27 Sartor RB, Cromartie WJ, Powell DW, Schwall JH. Granulomatous enterocolitis induced in rats by purified bacterial cell wall fragments. Gastroenterology $1985 ; 89$ : 587 95

28 Bjarnason I, Peters TJ. Intestinal permeability, Non-steroidal anti-inflammatory drug enteropathy and inflammatory bowel disease. Gut 1989; 30 (Festschrift): 22-8.

29 Bjarnason I, Smethurst P, Walker F, McElnay SC, Pearson P Macpherson A, Menzies IS. Glucose and citrate reduces the permeability changes caused by indomethacin Gastroenterology 1992; 102: 1546-50.

30 Bjarnason I, Smethurst P, Fenn CG, Lee CF, Menzies IS, Levi AJ. Misoprostol reduces indomethacin induced changes in human small intestinal permeability. Dig Dis Sci 1989; 34: human sma 11 .

31 Sharon P, Stenson WF. Enhanced synthesis of leukotriene by colonic mucosa in inflammatory bowel disease. Gastroenterology 1984; 86: 453-60

32 Stenson WF. Eicosanoids in inflammatory bowel disease with special reference to leukotriene B4. In: Peters TJ, ed. The cell biology of inflammation in the gastrointestinal tract. Hull: Corners Publication, 1990: 273-81.

33 Lindner AE, Marshak RH, Wolf BS, Janowitz HD. Granulomatous colitis. N Engl f Med 1963; 269: 397-85.

34 Dvorak AM. Ultrastructural pathology of Crohn's disease. In: Williamson $\mathrm{CN}$, ed. Inflammatory bowel disease - basic
research and clinical implications. Toronto: MTP Press, 1987 3-41.

35 Motil KJ, Grand RJ. Nutritional management of inflammatory bowel disease. Pediatr Clin North Am 1985; 32: 447-69.

36 Rhodes J, Rose J. Does food affect acute inflammatory bowel disease? The role of nutrition, elemental and exclusion diets. disease? The role of nut
Gut 1986; 27: 471-4.

37 Jewell DP, Kettlewell MGW. Split ileostomy for Crohn' colitis. In: Bayless TM, ed. Current management of inflamma
tory bowel disease. Toronto: BC Decker, 1989: 294-6.

38 Rutgeerts P, Goboes K, Peeters M, Hiele M, Penninckx F, Aerts $R$, et al. Effect of faecal stream diversion on recurrence of Crohn's disease in the neoterminal ileum. Lancet 1991 338: $771-4$.

39 Rutgeerts P, Peeters M, Hiele M, Kerremans R, Penninckx F Aerts $R$, et al. A placebo controlled trial of metronidazole for recurrence prevention of Crohn's disease after resection of the terminal ileum. Gastroenterology 1992; 102: A688. 